\title{
Mechanisms of Reduced Trillium Recruitment along Edges of Old-Growth Forest Fragments
}

\author{
ERIK S. JULES* AND BEVERLY J. RATHCKE \\ Department of Biology, University of Michigan, Ann Arbor, MI 48109-1048, U.S.A.
}

\begin{abstract}
Studies of plants in fragmented habitats bave focused on single ecological processes, such as seed production or seed dispersal, that may be altered by increased fragmentation and that operate as the mechanism(s) that increase extinction probability. We examined a suite of potential mechanisms to explain demographic shifts toward extinction in populations of Trillium ovatum, a long-lived berbaceous perennial found in the understory of western North American conifer forests. Past work has shown that populations of T. ovatum found within $\sim 65 m$ of forest-clearcut edges in southwestern Oregon have bad almost no new recruitment since the edges were formed. We bypothesized that changes in abiotic conditions and biotic interactions present along edges are responsible for reduced recruitment. In eight populations in eight separate fragments, we evaluated the relationship of distance of the populations to the forest edge with respect to six processes: flowering phenology (timing), seed production, pollination- and resource-limitation of seed set, seed dispersal, seed predation, and germination. Those factors that showed a significant relationship with edge distance were then compared with recruitment of younger age classes. Two processes were significantly different near edges and were bighly correlated with decreased recruitment: decreased seed production due to changes in pollination and increased seed predation by rodents. Our study (in conjunction with previous studies) suggests that several ecological processes show no significant relationship with edge distance and can be eliminated as possible mechanisms of reduced recruitment: flowering phenology, resource-limitation of seed set, seed dispersal, germination, herbivory, and survivorship of established plants. Edges influence some but not all components of a plant's life bistory. Thus, determining shifts in only one part of a life bistory will be inadequate for testing the prediction of increasing extinction probabilities in fragmented landscapes. Future studies should include enough information to conduct comprebensive analyses, such as matrix projections and sensitivity analyses.
\end{abstract}

Mecanismos de Reclutamiento de Trillium en Bordes de Fragmentos de Bosque Primario

Resumen: El estudio de plantas en hábitats fragmentados se ha enfocado a procesos ecológicos individuales, tal como producción o dispersión de semillas, que pueden ser alterados por el incremento de la fragmentación y que operan como mecanismo(s) que incrementa(n) la probabilidad de extinción. Examinamos una serie de mecanismos potenciales para explicar los cambios demográficos hacia la extinción en poblaciones de Trillium ovatum, una bierba perenne de vida larga presente en el sotobosque de bosques de coníferas en el occidente de Norteamérica. Trabajos anteriores han mostrado que las poblaciones de T. ovatum situadas a $\sim 65 m$ de bordes bosque/zona abierta en el $S W$ de Oregon casi no tuvieron reclutamiento desde que se formaron los bordes. Planteamos la bipótesis de que los cambios en condiciones abióticas y en las interacciones bióticas que presentan los bordes son responsables de la reducción de reclutamiento. En ocho poblaciones en ocho fragmentos separados, evaluamos la distancia de la población al borde en relación con seis procesos: fenología de floración, producción de semillas, polinización y limitación de recursos del conjunto de semillas, dispersión de semillas y germinacion. Los factores que tuvieron una relación significativa con la distancia al borde fueron comparados con el reclutamiento de clases jóvenes. Dos procesos fueron significativamente distintos cerca de los bordes y estuvieron fuertemente correlcionados con la reducción de

\footnotetext{
*Current address: Department of Environmental Studies, University of California, Santa Cruz, CA 95064, U.S.A., email ejules@cats.ucsc.edu Paper submitted October 31, 1997; revised manuscript accepted November 17, 1998.
} 
reclutamiento: disminución en la producción de semillas pro cambios en la polinización e incremento de depredación de semillas pro roedores. Nuestro estudio (combinado con estudios previos) sugiere que no bay relación significativa entre varios procesos ecológicos (fenología de floración, limitación de recursos, dispersión de semillas, germinación, herbívora y sobrevivencia de plantas establecidas) y la distancia al borde, por lo que pueden descartarse como posibles mecaismos de la reducción de reclutamiento. Los bordes influyen sobre algunos, pero no todos, los componentes de la bistoria de vida de una planta. Así la identificación de cambios en una sola parte de la bistoria de vida no es adecuada para probar la predicción de incremento en la probabilidad de extinción en paisajes fragmentados. Estudios futuros deben incluir suficiente información para análisis extensos como proyecciones matriciales y análisis de sensibilidad.

\section{Introduction}

Theoretical and empirical work indicates that populations of interior-restricted species in fragmented habitats are more likely to become extinct than those in contiguous landscapes, causing a loss of regional biological diversity (Wilcox \& Murphy 1985; Simberloff 1988; Harrison \& Fahrig 1995). Fragmentation can reduce population sizes, isolate populations from other populations, and increase "edge effects," all of which can increase population extinctions (Shaffer 1981; Lacy 1987; Lande 1988; Saunders et al. 1991; Lawton 1995). The actual mechanisms that cause increased extinction probabilities are poorly understood, however, especially those involving changes in species interactions. This is particularly true for plants because most research on the effects of fragmentation has been done on animal populations (e.g., Verboom et al. 1991; Rolstad 1991; Margules et al. 1994; Mills 1995). Studies of plants in fragmented habitats have focused on single ecological processes that may change in fragments, such as pollination, herbivory, seed production, and seed dispersal (Rathcke \& Jules 1993; Aizen \& Feinsinger 1994; Santos \& Telleria 1994; Murcia 1995), and changes in these processes are suggested as potential mechanisms that increase extinction probability. No studies have related these ecological changes directly to population declines or extinctions.

For the herbaceous understory perennial Trillium ovatum (Pursh., Liliaceae), recent habitat fragmentation in southwestern Oregon has significantly reduced the recruitment of new individuals into populations. Jules (1998) demonstrated that fragment size was not related to recruitment, but edge effects had significant effects on populations. Specifically, populations found within $\sim 65 \mathrm{~m}$ of forest-clearcut edges had had almost no recruitment of plants since the edges were created. To understand the possible causes for this lack of recruitment, we examined a suite of potential mechanisms, both abiotic and biotic. Edges in our study region have drier soil conditions, greater solar radiation, and higher daytime temperatures than forest interiors (Chen et al. 1993; Mills 1995), and we hypothesized that these abiotic factors could directly affect seed production, germination, and seedling survival. Further, abiotic factors could affect biotic interactions along edges, which may also influence seed and seedling recruitment. This influence could be either positive or negative in terms of recruitment. For example, edges often have higher levels of mammalian seed predators (Mills 1996), and this may be responsible for reduced trillium recruitment. On the other hand, edges can have greater levels of ant activity (Mesler \& Lu 1983), and this may increase dispersal rates of ant-dispersed seeds, such as the seeds of $T$. ovatum.

We evaluated correlations of the distance of populations to the forest edge with six ecological processes that might influence recruitment: flowering phenology, pollination- and resource-limitation of seed set, seed dispersal, seed predation, and germination. Those processes that showed a significant relationship with edge distance were then compared with recruitment of younger age classes. Two other processes were evaluated in a similar fashion in an earlier study. That study showed that herbivory by deer was not related to edge distance and that seed production (seeds per square meter) was greater in populations with high recruitment in 1 of 2 years studied (Jules 1998). Even in the years when seed production was low in populations with low recruitment, the number of seeds produced was greater than the mean number of plants recruited per year. Thus, seed production alone does not limit recruitment: at least one other factor is functioning as a mechanism to reduce recruitment near edges.

\section{Methods}

\section{Study Sites}

The study was conducted in the Sucker Creek watershed in the Siskiyou Mountains of southwestern Oregon. The watershed is approximately $50 \mathrm{~km}$ inland from the Pacific Ocean and covers $250 \mathrm{~km}^{2}$, almost all of which is within the boundaries of the Siskiyou National Forest. In general, lower-elevation forests in the region (540-1000 $\mathrm{m})$ are dominated by Douglas fir (Pseudotsuga menziesii) and hardwoods such as tanoak (Lithocarpus den- 
siflorus) and Pacific madrone (Arbutus menziesii). Midto high- elevation forests (1000-2100 m) are dominated by Douglas fir and white fir (Abies concolor). These higher forests are cooler and moister in summer than lower forests and have richer herbaceous communities. Common herbs include vanilla leaf (Achlys spp.), baneberry (Actaea rubra), woodland phlox (Pblox adsurgens), starflower (Trientalis latifolia), and western trillium (see Whittaker 1960). In the 1960s a period of intensive road building and clearcut logging began in the Sucker Creek watershed, resulting in the loss of approximately $40 \%$ of the late-successional forest over a 30-year period (U.S. Forest Service 1995).

The landscape in the Sucker Creek watershed is a mosaic of uncut forest surrounded by a matrix of clearcuts and young tree plantations. Remaining forest fragments range in size from 0.3 ha to 1000 ha (Mills 1995; Jules 1997 a). We accomplished the main component of our study using eight populations of trillium in eight separate forest fragments to determine if ecological processes were related to edge distance and recruitment levels. To minimize variation from outside sources, we selected populations that (1) were within one elevational range (1370-1680 m), (2) were on west-facing slopes, (3) were in old-growth forests dominated by Douglas fir and that had not experienced recent fires, and (4) harbored similar herbaceous plant communities. Sites of this type contain the greatest abundance of $T$. ovatum in the Sucker Creek watershed (Whittaker 1960). Forest fragments were distributed evenly over the watershed so that they were closer to other fragments not used in our study than they were to other study fragments. More than one population was found in any given fragment, although we selected only one population per fragment for study (average population size, 69 plants; average population area, $150.0 \mathrm{~m}^{2}$ ). We selected populations so that distance of populations from the edge was not related to other attributes, such as fragment size, elevation, or aspect. We describe additional studies conducted at sites along transects extending from the edge of individual old-growth fragments into the forest interior.

\section{Study Organism}

Western trillium (T. ovatum) is a common herbaceous plant found in mesic forests of the Rocky Mountains, western Canada, the Cascade Mountains, and the Coast Ranges as far south as Monterey County, California (Hickman 1993). Individuals produce aboveground vegetation in one of four stages: cotyledons, one-leaf plants, three-leaf vegetative plants, and three-leaf reproductive (flowering) plants. Trillium produce annual constrictions on their underground rhizomes and no clonal reproduction occurs, so the age of individuals can be determined (Brandt 1916; Hanzawa \& Kalisz 1993). Pre- vious work demonstrated that plants range up to 72 years old and that individuals do not become reproductive until they are at least 15 years old (Jules 1997a). Most plants produce only one stem $(10-20 \mathrm{~cm}$ in height), although reproductive individuals occasionally produce two or three stems per plant. One white flower per stem is produced by reproductive individuals in early spring, and petals last approximately 22 days, during which time they turn pink or dark purple (Levkowitz 1984).

Trillium ovatum is self-incompatible, and seed production can be limited by insufficient pollination (Levkowitz 1984). Trillium ovatum flowers do not produce nectar, although several insects forage for their pollen, such as rove beetles (Staphylinidae), sap beetles (Nitidulidae), flower long-horned beetles (Lepturinae), honey bees (Apis mellifera), and two species of bumble bees (Apinae). In addition, crab spiders (Thomisidae) often inhabit the corolla tubes of T. ovatum, and geometrid moths (Geometridae) covered in pollen are sometimes found captured by these spiders in morning, indicating that moths probably pollinate $T$. ovatum at night (Jules 1997b).

T. ovatum fruit can have 1-150 seeds, each of which is ovoid and 3-5 mm long (Mesler \& Lu 1983). Seeds have an attached food-body, or elaiosome, that is approximately the same size as the seed and is attractive to ants, which disperse seeds and elaiosomes into their nests (Berg 1975; Handel \& Beattie 1990). Ant dispersal and passive dispersal from the fruit are the most important modes of dispersal for T. ovatum (Berg 1958; Mesler \& Lu 1983). Yellow jackets (Vespula vulgaris) are also attracted to the elaiosomes of $T$. ovatum and are occasional seed dispersers for T. ovatum (Jules 1996). Evidence of seed predation by rodents has been noted for T. ovatum (Mesler \& Lu 1983; E.S.J., unpublished data) and for another trillium species, $T$. nivale (Smith et al. 1989).

\section{Flowering Phenology}

Timing of flowering may influence seed set as a result of the various environmental conditions and pollinator abundances that may be present at different flowering times (Rathcke \& Lacey 1985). To quantify flowering phenology in different fragment sites, all reproductive plants in seven of the eight study populations were marked with small plastic tags in the spring of 1993 (population 7 not included; Table 1). Beginning 1 May 1994 all populations were surveyed for the presence of flowering individuals weekly for 1 month, at which time all marked plants had flowered. Two measures of flowering phenology were used for statistical comparisons: weeks until $90 \%$ of individuals had flowered and weeks until $100 \%$ had flowered. The $90 \%$ measure was used to 
Table 1. Fragmentation attributes and demographic information for eight populations of Trillium ovatum within separate forest fragments.

\begin{tabular}{lcccc}
\hline Population & Fragment size (ha) & Edge distance $^{a}(\mathrm{~m})$ & Population size (no. of plants) $^{\text {Recruitment estimate }}{ }^{b}$ \\
\hline 1 & 2.97 & $67(16)$ & 53 & 0.0053 \\
2 & 3.72 & $65(14)$ & 48 & 0.0021 \\
3 & 6.48 & $61(29)$ & 26 & 0.0069 \\
4 & 11.90 & $30(13)$ & 64 & 0.0006 \\
5 & 62.09 & $84(30)$ & 56 & 0.0124 \\
6 & 116.74 & $97(26)$ & 56 & 0.0045 \\
7 & 215.99 & $16(16)$ & 129 & 0.0028 \\
8 & 1000 & $332(24)$ & 0.0182 \\
\hline
\end{tabular}

${ }^{a}$ Edge distance represents the number of meters the population was from the clearcut edge. The number of years the edge has been present is given in parentheses.

${ }^{b}$ Recruitment estimates are the densities of plants produced in the population per year since the adjacent clearcut (R.E.N. in Jules 1998).

reduce the influence of individuals that flowered much later than most in any given population.

\section{Pollination- and Resource-Limitation of Seed Set}

To determine if fragmentation influences pollination- or resource-limitation of seed set, we conducted a study in seven of the eight populations (population 7 not included; Table 1). Between 3 June and 20 June 1993 all reproductive plants within the populations were randomly assigned to one of two treatments: controls or pollen-supplemented. Control (C) plants were not manipulated and were exposed to natural levels of pollination. The stamens of trillium plants located $20-40 \mathrm{~m}$ from the populations were collected and used to supplement the remaining plants. Stigmas of pollen-supplemented (PS) plants were coated with pollen by rubbing collected stamens across the surface with forceps until the stigmas were completely covered. One stamen from each of 4-5 pollen-donor plants was used for each pollen-supplemented plant. We assumed there was more pollen available than needed for the number of ovules that could be fertilized (i.e., no pollen limitation). Fruits in each population were observed for dehiscence (matu- rity) weekly starting in late July. Upon maturity, between 9 and 24 August, all fruits were collected and seeds counted.

Mean seed set in the PS plants was considered a measure of resource limitation for each population (e.g., energy- or nutrient-limitation) because PS plants reflect the maximum seed production under no pollination limitation. Further, pollination limitation for each population was calculated as the ratio of the mean seed set in PS plants to $\mathrm{C}$ plants (PS/C). Although this ratio is the appropriate one for statistical analyses, we present the same information in a more informative way: percent pollination limitation $=100 \times(\mathrm{PS}-\mathrm{C}) / \mathrm{PS}($ Table 2$)$. Because the number of reproductive plants varied between populations, the number of $\mathrm{C}$ and PS plants also varied among populations. The number of plants per treatment was low because few plants were available when the study was initiated and because some plants were lost to herbivory by deer. Therefore, the numbers of control and pollen-supplemented plants in each population were not always equal (Table 2).

To determine the effect of edges on pollinator activity, we examined whether pollen deposition varied with edge distance by measuring the number of pollen grains

Table 2. Ecological factors for eight populations of Trillium ovatum found in eight separate forest fragments.

\begin{tabular}{|c|c|c|c|c|c|c|c|c|c|c|c|c|}
\hline Population & $\begin{array}{c}90 \% \\
\text { flowering } \\
\text { (days) }\end{array}$ & $\begin{array}{c}100 \% \\
\text { flowering } \\
\text { (days) }\end{array}$ & $\begin{array}{c}\text { No. } \\
\text { of } \\
\text { controls }^{a}\end{array}$ & $\begin{array}{c}\text { No. } \\
\text { of PS } \\
\text { plants }^{a}\end{array}$ & $\begin{array}{l}\text { Average } \\
\text { seed } \\
\text { set }(C)^{a}\end{array}$ & $\begin{array}{l}\text { Average } \\
\text { seed } \\
\text { set }(P S)^{a}\end{array}$ & $\begin{array}{c}\text { Pollen } \\
\text { limitation } \\
(\%)^{a}\end{array}$ & 1993 & 1995 & $\begin{array}{c}\text { Yellow } \\
\text { jackets } \\
1995^{c}\end{array}$ & 1993 & 1995 \\
\hline 1 & 14 & 14 & 7 & 9 & 10.7 & 15.3 & 30.0 & 2.3 & 4.0 & 2.0 & 2.0 & 4.7 \\
\hline 2 & 21 & 21 & 7 & 7 & 0.3 & 15.6 & 98.0 & - & 10.0 & 2.0 & - & 6.7 \\
\hline 3 & 28 & 35 & 4 & 4 & 2.8 & 21.7 & 87.0 & 3.7 & 5.3 & 3.0 & 5.0 & 2.7 \\
\hline 6 & 28 & 35 & 9 & 8 & 2.0 & 7.3 & 73.0 & 1.7 & 0.7 & 0.0 & 2.0 & 0.0 \\
\hline 7 & - & - & - & - & - & - & - & - & 2.3 & 0.0 & - & 4.0 \\
\hline 8 & 21 & 28 & 7 & 7 & 6.0 & 8.1 & 26.0 & 1.7 & 0.3 & 0.0 & 1.0 & 0.0 \\
\hline
\end{tabular}

${ }^{a}$ C, controls; PS, pollen-supplemented; percent pollination limitation $=100 \times(P S-C) / P S$ (see text).

${ }^{b}$ Seed dispersal and predation measures from 1993 are the mean of five seeds taken from each of three platforms during a 24-hour period. Seed dispersal and predation measures from 1995 are the mean of 10 seeds removed from three platforms during a 24-hour period. Predation measures do not include adjustments for yellow jacket removal.

${ }^{c}$ Number of seeds taken of 10 seeds on one platform. 
per stigma on plants along a transect from the edge to the interior of one fragment in 1994 (fragment-containing population 2; Table 1). After pollen had been removed by pollinators from all anthers in the fragment, stigmas from plants were collected within a $30 \mathrm{~m}$ wide transect four distances from the west-facing forest edge: $0-10,20-30,40-50$, and 60-70 m. Stigmas from three individuals at each distance were collected and stored in dry glass vials until 1 December 1994, at which time they were removed and treated with a fuchsin stain on a microscope slide (Beattie 1971; Kearns \& Inouye 1993). Pollen grains were counted under a compound microscope. Self versus outcross pollen could not be differentiated by this technique.

\section{Seed Dispersal}

To measure the influence of edges on seed dispersal rates, we conducted separate experiments in 1992, 1993, and 1995. In 1992, one fragment was chosen in which to compare dispersal activity in forest interior, forest edge, and clearcuts (fragment containing population 2; Table 1). This fragment was square-shaped, situated on a west-facing slope, and surrounded on all four sides by clearcuts. A 25-m transect was marked diagonally in three locations: the center of the fragment, transecting the middle of the southern edge, and in the center of the clearcut south of the fragment (thus, all transects were at the same elevation). For these interior, edge, and clearcut sites, 5 locations were picked at random from a grid consisting of points at 5-m intervals along each transect and one point directly $5 \mathrm{~m}$ north and south of these 5 locations, for a total of 15 locations per grid). Experimental seed depots were positioned at 5 randomly selected locations in each grid. Depots were $15 \times 15 \mathrm{~cm}$ plywood squares suspended on $25-\mathrm{cm}$, metal stakes that were hammered through the center of the plywood and into the soil. The plywood depot was $4-8 \mathrm{~cm}$ above the soil, and ants could reach it by ascending the stake. To keep rodents from reaching the depots, plastic strawberry baskets were secured upside down over the plywood with heavy-duty staples. Yellow jackets and ants could easily enter through the strawberry baskets. Five seeds with attached elaiosomes were placed on each depot at 1630 hours on 31 July. Depots were checked for seed removal every 8 hours until 1630 hours on 2 August ( 48 hours total).

In 1993, six of the eight study populations were used for a seed dispersal study (not including populations 2 and 7; Table 1). Each population was overlaid with a rectangular grid that had been used in earlier demographic studies (Jules 1998). These grids were used to place three depots identical to those used in 1992 at random coordinates within each population. Five seeds were placed on each depot mid-morning on either 17 or
18 August (both warm, sunny days), and seeds were checked for removal 24 hours later.

In 1995 a similar experiment was conducted using all eight study populations. Three depots with 10 seeds were placed at random locations in each population. Also, to estimate the number of seeds removed by yellow jackets, one additional depot was placed at a randomly chosen location in each population. This depot was similar to the others except that the stake was coated with a large quantity of petroleum jelly so that ants could not ascend. Ten seeds were also placed on this depot. The experiment was initiated on 19 and 20 August, and seeds were observed for removal 24 hours later.

\section{Seed Predation}

We conducted experiments to measure the influence of edges on seed predation concurrently with the seed dispersal experiments in 1993 and 1995. Three seed platforms were placed at random locations in each population (six populations in 1993, eight populations in 1995). The platforms used in these studies were similar to those in the seed dispersal studies except that no strawberry baskets were used and the stakes were coated with petroleum jelly to keep ants from ascending. Five seeds were placed on platforms in 1993, and 10 seeds were placed on platforms in 1995. Because yellow jackets may also forage on these platforms, for each population the number of seeds removed from the 1995 yellow jacket depots (described above) was added to the number of the seeds taken from each depot used to estimate predation rates in 1995 . We were unaware of the potential influence of yellow jackets until after the 1993 study, and we have no method of adjusting for removal of seeds by yellow jackets in 1993 .

\section{Seed Germination}

Germination of seeds is influenced by many factors, including the availability of water and warmth (Silvertown 1982). Although temperatures are much higher in clearcuts and along edges, these sites are also significantly drier (Mills 1996). We hypothesized that if forest fragmentation results in drier conditions, then sites nearer to edges would have a lower percent germination of $T$. ovatum seeds, especially because $T$. ovatum is found in mesic sites.

Seeds of T. ovatum require one cold period (winter) for germination, at which time only the root emerges. After one additional cold period, the shoot (cotyledons) emerges (Jules 1997b). This unusual kind of dormancy, epicotyl dormancy, is found in two other species of trillium, T. grandiflorum and T. erectum (Barton 1944). We collected seeds from various locations near the eight study populations in summer 1994. These seeds were 
stored with moist sand in plastic bags at $4^{\circ} \mathrm{C}$. Seeds were kept at this temperature from 1 August 1994 until 30 May 1995. Although this amount of time is greater than that needed for germination (no more than 4 months, but probably much less), the duration of cold exposure does not seem to influence germination: nearly $100 \%$ of seeds placed on moist filter paper in a growth chamber germinated regardless of whether they were stored at cold temperatures for 4 months or 7.5 months (Jules 1997b).

On 31 May 1995, seeds were planted along a transect in one of three square-shaped forest fragments (fragments containing populations 1, 2, and 3; Table 1). The transects started at the middle of each west-facing edge and continued $80 \mathrm{~m}$ eastward, directly into the interior of the forests. Ten seeds were planted at 0, 20, 40, 60, and $80 \mathrm{~m}$. At each point, the 10 seeds were planted $4 \mathrm{~cm}$ apart in a straight line (north-south). Seeds were chosen at random from a bag containing all collected seeds and were planted to a depth of $\sim 2 \mathrm{~cm}$. To avoid predation by rodents, a piece of $12 \times 50 \mathrm{~cm}$ hardware cloth with $1.2-\mathrm{cm}^{2}$ openings was placed on the soil directly above the seeds and secured with small spikes in the corners. Herbivory by deer was thwarted by placing a cage of hardware cloth over the 10 seeds. To understand why the few plants remaining in some clearcuts are unable to recruit new plants, one replicate of this 10-seed array was planted $20 \mathrm{~m}$ into the adjacent clearcut at each fragment. Those seeds that were to germinate would have produced roots in the spring or summer of 1995. Germination was measured in spring 1996, however, when aboveground parts were visible following the period of epicotyl dormancy. Seeds were checked weekly from 14 May to 11 June 1996.

\section{Statistical Analyses}

We used Spearman Rank correlations to detect significant relationships between the distance of populations from edges and the ecological processes that we measured. Spearman correlations, which are conservative nonparametric tests, were used throughout much of this study due to the low number of samples and the large number of correlations tested. Furthermore, because of the number of correlations tested, Bonferonni-type adjustments made obtaining significant probability values extremely difficult. Thus, we calculated both unadjusted $p$ values as well as the $\alpha$ required for statistical significance with a Bonferonni technique. Both of these values are presented in our results. All statistical analyses were performed using SYSTAT (Wilkinson 1990).

For those ecological processes that showed significant relationships with edge distances, we tested for relationships with recruitment estimates. We used Spearman correlations to test for significant relationships between recruitment and the three independent variables we had obtained from the above test. Again, we listed both the unadjusted $p$ values and the $\alpha$ required to obtain significance with a Bonferonni technique.

For the 1992 seed dispersal study, differences in the rate at which seeds were removed were assessed with a repeated-measures analysis of variance, in which location (forest interior, edge, and clearcut), time, and the interaction between location and time were tested. For the pollen deposition study, the number of pollen grains on stigmatic surfaces was regressed on distance from edge. In the seed germination study, differences in the number of seeds that germinated at each distance were assessed with an analysis of variance in which fragment and distance (nested in fragment) were treated as fixed variables. The arrays of seeds in clearcuts were not used in this analysis because they fell outside the range of edge distances represented by the eight study populations.

\section{Results}

\section{Flowering Phenology}

The timing of flowering was not correlated with the distance of a population from the edge (Table 3 ). Little variance was associated with our measure of the timing of flowering among populations, however; plants within the study populations flowered within 3 weeks of one another, and measuring the presence of flowering on only a weekly basis may have been inadequate for detecting differences.

Table 3. Correlation coefficients (Spearman's $\boldsymbol{r}_{\boldsymbol{s}}$ ) between ecological processes and edge distance in eight populations of Trillium ovatum in separate forest fragments.

\begin{tabular}{lcccc}
\hline & & \multicolumn{2}{c}{ Edge distance $^{a}$} \\
\cline { 3 - 5 } & & $\mathrm{n}^{b}$ & $\mathrm{r}_{\mathrm{s}}$ & $\mathrm{p}^{c}$ \\
\hline $90 \%$ flowering (days) & 7 & -0.239 & 0.606 \\
100\% flowering (days) & & 7 & 0.000 & 1.000 \\
Average seed set (C) & & 7 & 0.214 & 0.645 \\
Average seed set (PS) & & 7 & -0.929 & $0.003^{* *}$ \\
Pollen limitation & & 7 & -0.679 & 0.094 \\
Seed dispersal & 1993 & 6 & -0562 & 0.246 \\
& 1995 & 8 & -0.690 & 0.058 \\
Yellow jackets & 1995 & 8 & -0.206 & 0.624 \\
Seed predation & 1993 & 6 & -0.903 & $0.014^{*}$ \\
& 1995 & 8 & -0.805 & $0.016^{*}$ \\
\hline
\end{tabular}

${ }^{a}$ Edge distance is the distance to the closest clearcut edge from the study population.

${ }^{b} \mathrm{n}$, number of populations used in each test.

${ }^{c} \mathrm{p}$ values have not been adjusted for the number of correlations tested. A Bonferonni adjustment obtains a significance level $(\alpha)$ of $\mathrm{p} \leq 0.005 .{ }^{*} \mathrm{p} \leq 0.05,{ }^{* *} \mathrm{p} \leq 0.01$. 


\section{Pollination and Resource-Limitation of Seed Set}

Seed set was pollination-limited in all populations; mean seed set was higher in pollen-supplemented (PS) plants than in the control (C) plants (Table 2). Mean seed set of control plants ranged from 0.3 to 10.7 seeds per plant, and mean seed set in pollen-supplemented plants ranged from 7.3 to 21.7 seeds per plant (each plant had only one flower and fruit). Percent pollination limitation$(100 \times(\mathrm{PS}-\mathrm{C}) / \mathrm{PS})$ - ranged from 3.0 to $98.0 \%$, with a mean of $49.4 \%$ (Table 2 ).

For pollen-supplemented plants, seed set per fruit was significantly higher in plants near the edges than in the forest interior (Table 3). This suggests that plants near the edges had more resources than plants in the shady interior. Because increased resources cannot explain reduced recruitment near edges, we did not test our measure of resource limitation (PS seed set) as a variable affecting recruitment. Instead, we tested the relationship of pollination limitation with recruitment because pollination limitation reflects the PS-edge distance relationship and because pollination limitation describes a more important process in regard to reduced recruitment (i.e., effective pollination).

Despite higher resources near edges, pollination limitation was higher near edges (Table 3) and was lower in populations with low recruitment (Table 4). Increased resources near edges, however, did not result in higher seed set for control plants near edges (Table 3). In the pollen deposition study, pollen deposition on stigmas did not differ significantly across edge distances $(F=$ 0.026 ; df $=1,26.7 ; p=0.874$ ). The average number of pollen grains on stigmatic surfaces of the 12 plants surveyed was $22.2(\mathrm{SE} \pm 8.8$, range $=0.0-99.0)$.

\section{Seed Dispersal}

We detected no significant differences in seed removal rates between the three sites-forest interior, forest

Table 4. Correlation coefficients (Spearman's $r_{s}$ ) between ecological factors and recruitment estimates in eight populations of Trillium ovatum in separate forest fragments.

\begin{tabular}{|c|c|c|c|}
\hline & \multirow[b]{2}{*}{$\mathrm{n}^{b}$} & \multicolumn{2}{|c|}{ Recruitment estimate $^{a}$} \\
\hline & & $r_{s}$ & $\mathrm{p}^{c}$ \\
\hline Pollen limitation $^{d}$ & 7 & 0.692 & 0.085 \\
\hline Seed predation 1993 & 6 & -0.510 & 0.301 \\
\hline Seed predation 1995 & 8 & -0.781 & $0.007^{* *}$ \\
\hline \multicolumn{4}{|c|}{$\begin{array}{l}{ }^{a} \text { Recruitment estimates are the densities of plants produced in the } \\
\text { population per year since the adjacent clearcut barvests. } \\
{ }^{b} \mathrm{n}, \text { number of populations used in each test. } \\
{ }^{c} \mathrm{p} \text { values bave not been adjusted for the number of correlations } \\
\text { tested. A Bonferonni adjustment obtains a significance level }(\alpha) \text { of } \\
\mathrm{p}_{\mathrm{p}} \leq 0.017 .{ }^{* *} \mathrm{p} \leq 0.01 .\end{array}$} \\
\hline
\end{tabular}

edge, and clearcut-in the 1992 seed dispersal study (location $\times$ time interaction; $F=0.48, \mathrm{df}=12, p=0.913$ ). Seeds were removed (by ants and/or yellow jackets) from platforms placed in all three sites. In the 1993 seed dispersal study, mean seed removal was not correlated with edge distance (Tables 2 \& 3), but removal was negatively correlated with edge in 1995 (Table 3). Seeds were removed from the experimental platforms in all populations in both the 1993 and 1995 studies. In 1993 the average number of seeds removed from platforms in each population ranged from 1.7 to 3.7 seeds. In 1995 the average number of seeds removed from the platforms in each population ranged from 0.3 to 10.0 seeds. In only one population in $1995(n=2)$ were all seeds removed by the end of the 24-hour period (Table 2 ).

Because we assumed that seed dispersal has positive effects on recruitment, we did not test the relationship of seed dispersal estimates and recruitment. Removal from platforms available exclusively to yellow jackets occurred in only the three smallest fragments, although yellow jacket removal was not correlated with edge distance (Table 3).

\section{Seed Predation and Germination}

Significantly more seeds were removed by rodents in populations that were closer to the edge in 1993 (Table 3). Seed removal rates in 1995 were also significantly higher near edges (Table 3). In 1995 seeds were removed from five of the eight populations, and no seeds were removed from the three populations furthest from clearcut edges (Table 2). Seeds were removed from platforms in all six populations studied in 1993 (Table 2). Seed removal was higher in populations with low recruitment estimates in both years. The correlations, however, were significant only for 1995 removal versus recruitment (Table 4). Most seeds are presumably eaten after removal and are thus used as estimates of seed predation.

Germination did not differ significantly among edge distances $(F=0.146$, df $=12, p=0.990)$. Seeds germinated at all sites (i.e., edge distances) within the forest fragments in at least one of the three fragments. Of the sites within forests, mean germination was highest at the 40-m edge distance (23.3\%) and was lowest at $80 \mathrm{~m}$ (6.7\%). Mean seed germination was $15.5 \%$ on the edge (i.e., edge distance $=0 \mathrm{~m}$ ). No seeds in the experimental arrays produced aboveground vegetation in any of the three clearcuts used in the seed germination study.

\section{Discussion}

We examined a suite of interactions that might affect plant population growth in habitat fragments. Of the mechanisms examined, two plant-animal interactions 
could possibly contribute to the lack of $T$. ovatum recruitment near clearcut edges. These were (1) reduced seed set due to pollination limitation and (2) increased seed predation by rodents near edges. Other potential mechanisms examined here, as well as some studied in previous work (Jules 1998)-including flowering phenology, resource limitation, seed dispersal by ants and yellow jackets, seed germination, herbivory, and survivorship of established plants-showed no significant relationships to reduced trillium recruitment near edges.

Changes in pollination activity may explain reduced recruitment along edges. We detected a decrease in effective pollination events along edges that resulted in fewer seeds produced per square meter. This conclusion is based upon considerations of both pollination and resource limitation of seed set. Plants near edges increased seed production when supplemented with additional pollen to a greater extent than did interior plants (Table 2), suggesting that seed set is less resource-limited near the edge and that equal pollen deposition should result in higher seed set in edge plants. Control plants near edges, however, tended to produce the same number of seeds (or slightly fewer seeds) than interior plants (Table 3), indicating that plants on the edge are limited by the number of successful pollination events. In the one fragment in which we studied pollen deposition, it did not vary significantly with edge distance. Our measures of pollen deposition did not separate self- versus outcross-pollen grains and, coupled with our pollination-limitation data, may indicate that deposition of self pollen was higher near edges. A higher percentage of self pollen could result in lower seed set in this selfincompatible plant. Although changes in pollination and seed set appear related to reduced trillium recruitment along edges, they cannot fully explain the reduction because seed set was always higher than recruitment levels.

A second plant-animal interaction, seed predation by rodents, was higher near edges and could directly contribute to the failure of recruitment near edges. Removal rates of seeds from seed depots available only to rodents were higher in populations closer to edges. Populations with higher predation rates also have lower recruitment estimates (Table 4), suggesting that rodents may be reducing the number of seeds that can potentially be recruited into populations near edges. In the same region in which we conducted our study, the Sucker Creek watershed, Mills (1993, 1995, 1996) demonstrated that deer mice (Peromyscus maniculatus and P. trueii) are much more abundant in clearcuts and on forest edges than in forest interior.

Seed predation levels along edges could be reduced if seed dispersers rapidly removed seeds from fruits. Dispersal by ants, for instance, has been shown to confer several advantages to seeds, such as the movement of seeds to underground sites where seed predation is low (Culver \& Beattie 1980; Anderson 1988; Hanzawa et al.
1988). Yellow jacket dispersal of seeds (vespicochory) should have similar consequences (Jules 1996). Removal rates by seed dispersers in our 3 years of study did not differ consistently between edges and interior, indicating that dispersal is influencing rates of seed predation equally across sites. On the other hand, dispersal of seeds away from suitable forested sites (possibly edge sites) into clearcut habitat would clearly have negative effects on recruitment. This is not likely to occur because $70 \%$ of all trillium seeds removed by ants are dispersed $60 \mathrm{~cm}$ or less, and none more than $2.0 \mathrm{~m}$ (Mesler \& Lu 1983). Yellow jackets might move seeds up to 900 $m$ from a parent plant (Spradbury 1973), although vespicochory represented only a small proportion of the overall seed removal in our study. Thus, most seeds are placed in similar environments close to the maternal plant, and seed dispersal events are not likely to be responsible for reduced recruitment along edges.

Edges provide habitat suitable for germination, and changes in germination cannot explain reduced levels of recruitment. In fact, sites furthest into forest interior had the lowest percent germination of seeds. The highest percent germination was observed $40 \mathrm{~m}$ from the forest edge, although differences in germination were not significant among distances from the edge. Survivorship in the year(s) immediately following germination has not yet been studied thoroughly, and seeds that germinated in our study will be followed to provide this information. Nevertheless, because a reduction in the number of plants in age classes immediately following the 2-year old cotyledon stage has not been observed in populations with low recruitment, it appears that changes in survivorship of young plants are probably not responsible for lower recruitment (Jules 1998). Our study also showed that clearcuts produce environments too extreme for any germination of trillium seeds.

In summary, changes in pollination and seed predation occur near edges and could contribute to lower recruitment levels of $T$. ovatum. Nevertheless, the degree to which changes in plant-pollinator and plant-seed predator relationships are influencing demography is difficult to assess. Pollination limitation and seed set for T. ovatum vary greatly from year to year (Levkowitz 1984), suggesting that adverse changes in pollinator interactions may be significant in only some years. Also, our data from 1993 and 1995 suggest that seed predation rates can vary between years.

Two other studies have tested the hypothesis that loss of pollinators resulting from habitat fragmentation will reduce seed set in flowering plants. Jennersten (1988) found that a perennial herb, Dianthes deltoides, in Sweden showed pollination limitation of seed set in fragments of meadow habitat but not in continuous habitat. Aizen and Feinsinger (1994) compared two forest fragments with continuous forest in Argentina and found significant or marginal declines in pollen tube numbers 
per flower in 9 of 16 plant species, in fruit set for 5 of 15 species, and in seed set for 3 of 14 species in forest fragments. These studies, along with ours, demonstrate that fragmentation can affect pollination both by reducing the size of remnant habitat and by increasing edge habitat.

A central tenet in applied ecology is that populations in fragmented habitat are more likely to become extinct than those in contiguous habitat (Simberloff 1988; Harrison \& Fahrig 1995). Surprisingly, there is little direct evidence supporting this prediction for plants. Unfortunately, determining shifts in one plant-animal interaction due to fragmentation will be inadequate for testing this prediction because some shifts may not necessarily result in demographic changes. For instance, although increased seed production could increase the probability of recruitment, it may have no significant demographic effects if plant populations are not seed-limited. Fully understanding the demographic effects of altered interspecific interactions in fragments will require longer-term studies of survivorship and fecundity and the use of projection models (Schemske et al. 1994). Nevertheless, our study of a suite of interactions indicates that many interactions will change as a result of fragmentation and that they have the potential to influence future population growth and persistence.

\section{Acknowledgments}

This manuscript was greatly improved by comments from D. Goldberg, T. Root, L. Curran, and two anonymous reviews. We thank the following people for their assistance with fieldwork: S. Baughman, K. Beasely, J. Beigel, G. Borod, A. Jules, M. Kauffman, C. Meilinger, S. Mason, A. Robohm, B. Thacker, and J. Urwin. G. Fowler and G. Estabrook gave much help with statistical analyses. Support for this work was provided by The American Philosophical Society, The Nature Conservancy, and the Department of Biology and Rackham Graduate School, University of Michigan.

\section{Literature Cited}

Aizen, M. A., and P. Feinsinger. 1994. Forest fragmentation, pollination, and plant reproduction in a Chaco dry forest, Argentina. Ecology 75:330-351.

Anderson, A. N. 1988. Dispersal distance as a benefit of myrmecochory. Oecologia 75:507-511.

Barton, L. V. 1944. Some seeds showing special dormancy. Contributions from Boyce Thompson Institute 13:259-271.

Beattie, A. J. 1971. A technique for the study of insect-borne pollen. Pan Pacific Entomologist 47:82.

Berg, R. 1958. Seed dispersal, morphology, and phylogeny of Trillium. Skrifter Utgitt av Det Norske Videnskaps-Akademi 1:1-36.

Berg, R. 1975. Myrmecochorous plants in Australia and their dispersal by ants. Australian Journal of Botany 23:475-508.

Brandt, R. P. 1916. Notes on the California species of Trillium L. University of California Publications in Botany 7:39-68.
Chen, J., J. F. Franklin, and T. A. Spies. 1993. Contrasting microclimates among clearcut, edge, and interior of old-growth Douglas-fir forest. Agricultural and Forest Meteorology 63:219-237.

Culver, D. C., and A. J. Beattie. 1980. The fate of Viola seeds dispersed by ants. American Journal of Botany 67:710-714.

Handel, S. N., and A. J. Beattie. 1990. Seed dispersal by ants. Scientific American 262:76-83.

Hanzawa, F. M., and S. Kalisz. 1993. The relationship between age, size, and reproduction in Trillium grandiflorum. American Journal of Botany 80:405-410.

Hanzawa, F. M., A. J. Beattie, and D. C. Culver. 1988. Directed dispersal: demographic analysis of an ant-seed mutualism. American Naturalist 131:1-13.

Harrison, S., and L. Fahrig. 1995. Landscape pattern and population conservation. Pages 293-308 in L. Hansson, L. Fahrig, and G. Merriam, editors. Mosaic landscapes and ecological processes. Chapman Hall, London.

Hickman, J. C. 1993. The Jepson manual: higher plants of California. University of California Press, Berkeley.

Jennersten, O. 1988. Pollination in Dianthus deltoides (Caryophyllaceae): effects of habitat fragmentation on visitation and seed set. Conservation Biology 2:359-366.

Jules, E. S. 1996. Yellow jackets (Vespula vulgaris) as a second seed disperser for the myrmecochorous plant, Trillium ovatum. American Midland Naturalist 135:367-369.

Jules, E. S. $1997 a$. Consequences of forest fragmentation for the understory plant, Trillium ovatum (Liliaceae). Pages 201-206 in T. N. Kaye, A. Liston, R. M. Love, D. Luoma, R. J. Meinke, and M. V. Wilson, editors. Conservation and management of native plants and fungi. Native Plant Society of Oregon, Corvallis.

Jules, E. S. 1997b. History and consequences of forest fragmentation: a study of Trillium ovatum in southwestern Oregon. Ph.D. dissertation. University of Michigan, Ann Arbor.

Jules, E. S. 1998. Habitat fragmentation and demographic change for a common plant: trillium in old-growth forest. Ecology 79:16451656.

Kearns, C. A., and D. W. Inouye. 1993. Techniques for pollination biologists. University Press of Colorado, Niwot.

Lacy, R. C. 1987. Loss of genetic diversity from managed populations: interacting effects of drift, mutation, immigration, selection, and population subdivision. Conservation Biology 1:143-158.

Lande, R. 1988. Genetics and demography in biological conservation. Science 241:1455-1460.

Lawton, J. H. 1995. Population dynamic principles. Pages 147-163 in J. H. Lawton and R. May, editors. Extinction rates. Oxford University Press, New York.

Levkowitz, T. A. 1984. Pollination biology of Trillium ovatum Pursch. (Liliaceae) in Northern California. M.S. thesis. Humbolt State University, Arcata, California.

Margules, C. R., G. A. Milkovits, and G. T. Smith. 1994. Contrasting effects of habitat fragmentation on the scorpion Cercophonius squama and an amphipod. Ecology 75:2033-2042.

Mesler, M. R., and K. L. Lu. 1983. Seed dispersal of Trillium ovatum (Liliaceae) in second-growth redwood forest. American Journal of Botany 70:1460-1467.

Mills, L. S. 1993. Extinction in habitat remnants: proximate mechanisms and biogeographic consequences. Ph.D. dissertation. University of California, Santa Cruz.

Mills, L. S. 1995. Edge effects and isolation: red-backed voles on forest remnants. Conservation Biology 9:395-403.

Mills, L. S. 1996. Fragmentation of a natural area: dynamics of isolation for small mammals on forest remnants. Pages 199-219 in R. G. Wright, editor. Natural parks and protected areas. Blackwell Science, Cambridge, Massachusetts.

Murcia, C. 1995. Edge effects in fragmented forest: implications for conservation. Trends in Ecology and Evolution 10:58-62. 
Rathcke, B. J., and E. S. Jules. 1993. Habitat fragmentation and plantpollinator interactions. Current Science 65:273-277.

Rathcke, B. J., and E. P. Lacey. 1985. Phenological patterns of terrestrial plants. Annual Review of Ecology and Systematics 16:179-214.

Rolstad, J. 1991. Consequences of forest fragmentation for the dynamics of bird populations: conceptual issues and the evidence. Pages 149-163 in M. E. Gilpin and I. Hanski, editors. Metapopulation dynamics: empirical and theoretical investigations. Academic Press, London.

Santos, T., and J. L. Telleria. 1994. Influence of forest fragmentation on seed consumption and dispersal of spanish juniper, Juniperus thurifera. Biological Conservation 70:129-134.

Saunders, D. A., R. J. Hobbs, and C. R. Margules. 1991. Biological consequences of ecosystem fragmentation: a review. Conservation Biology 5:18-32.

Schemske, D. W., B. C. Husband, M. H. Ruckelshaus, C. Goodwillie, I. M. Parker, and J. G. Bishop. 1994. Evaluating approaches to the conservation of rare and endangered plants. Ecology 75:584-606.

Shaffer, M. L. 1981. Minimum population sizes for species conservation. BioScience 31:131-134.

Silvertown, J. 1982. Introduction to plant population ecology. Longman Scientific and Technical, Essex, United Kingdom.
Simberloff, D.S. 1988. The contribution of population and community biology to conservation science. Annual Review of Ecology and Systematics 19:473-511.

Smith, B. H., P. D. Forman, and A. E. Boyd. 1989. Spatial patterns of seed dispersal and predation of two myrmecochorous forest herbs. Ecology 70:1649-1656.

Spradbury, J. P. 1973. Wasps: an account of the biology and natural history of solitary and social wasps. University of Washington Press, Seattle.

U.S. Forest Service. 1995. Grayback/Sucker pilot watershed analysis. Version 1.0. Siskiyou National Forest, Illinois Valley Ranger District, Cave Junction, Oregon.

Verboom, J., A. Schotman, P. Opdam, and J. A. J. Metz. 1991. European Nuthatch metapopulations in a fragmented agricultural landscape. Oikos 61:149-156.

Whittaker, R. H. 1960. Vegetation of the Siskiyou Mountains, Oregon and California. Ecological Monographs 30:279-338.

Wilcox, B. A., and D. D. Murphy. 1985. Conservation strategy: the effects of fragmentation on extinction. American Naturalist 125:879-887.

Wilkinson, L. 1990. SYSTAT: the system for statistics. SYSTAT, Evanston, Illinois.
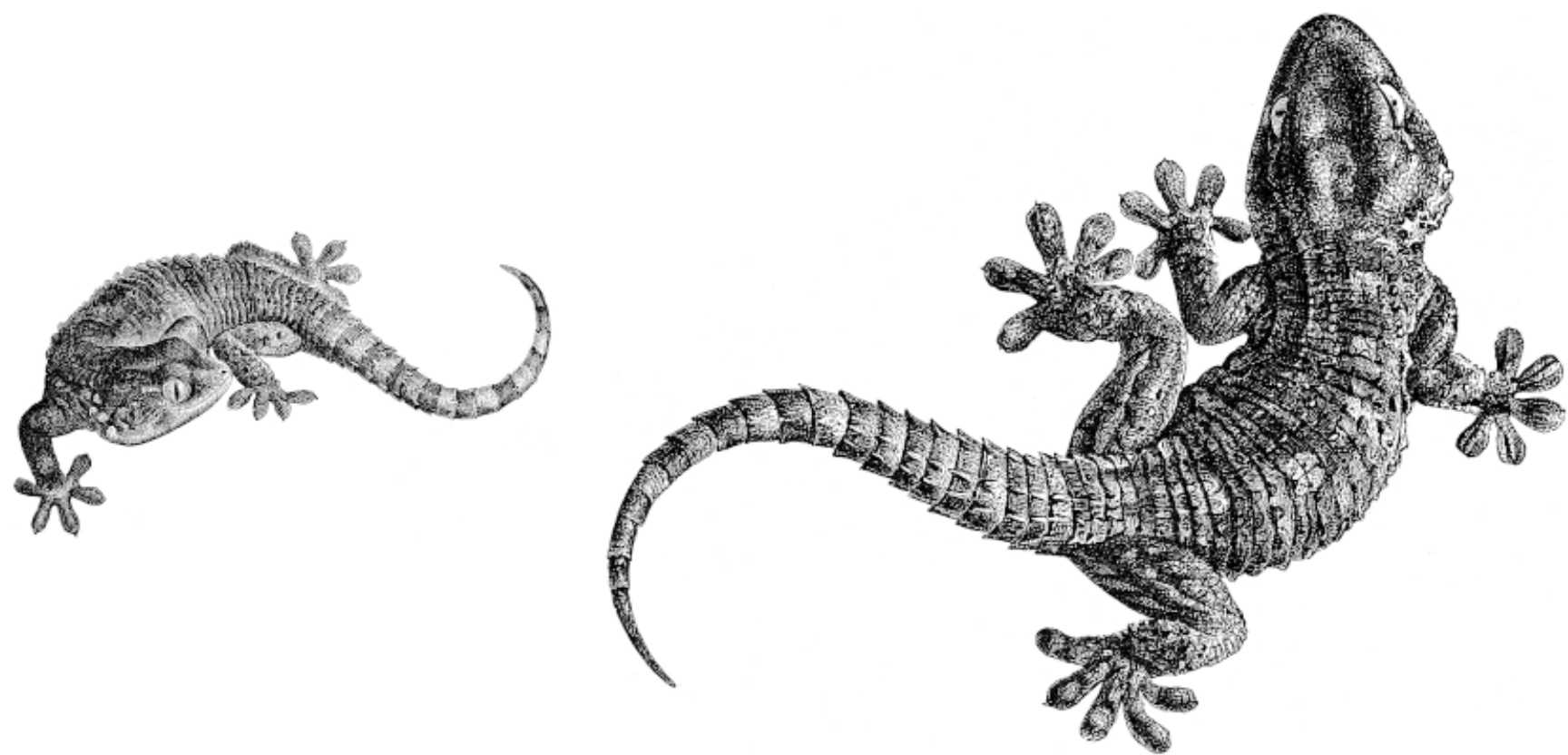